\title{
СТАТИСТИЧЕСКИЕ ПОДХОДЫ К РАНЖИРОВАНИЮ ВОЗМОЖНЫХ НАРУШЕНИЙ ПРИ РАСХОДОВАНИИ СРЕДСТВ НА ФЕДЕРАЛЬНЫЕ ПРОЕКТЫ
}

\author{
(C) 2021 Петров Александр Михайлович \\ доктор экономических наук, профессор Департамента бизнес-аналитики \\ Финансовый университет при Правительстве Российской Федерации, Россия, Москва \\ профессор кафедры бухгалтерского учета и налогообложения \\ Российский экономический университет им. Г. В.Плеханова, Россия, Москва \\ E-mail:palmi@inbox.ru
}

В статье проведено ранжирование возможных нарушений при расходовании средств на федеральные проекты на основе статистических данных социально-экономических измерений.

Дана собственная точка зрения на методы управления рисками, формирование системы индикаторов и процесс отбора ключевых индикаторов риска. Выявлены принципы эффективного формирования ключевых индикаторов риска.

Ключевые слова: бюджетные нарушения, федеральный проект, отраслевой риск, ключевые индикаторы риска.

Для построения эффективной системы внутреннего финансового контроля необходимо ранжировать нарушения в части расходования средств, выделенных на федеральные проекты.

Глава 30 Бюджетного Кодекса РФ (далее - БК РФ), введенная в 2013 г., выделяет четыре вида бюджетных нарушений, представленных на рисунке 1 , среди которых такое нарушение как нецелевое использование бюджетных средств способно в наибольшей степени воспрепятствовать реализации федеральных проектов. Таким образом, контролю необходимо подвергать все бюджетные средства, направленные на реализацию федеральных проектов.

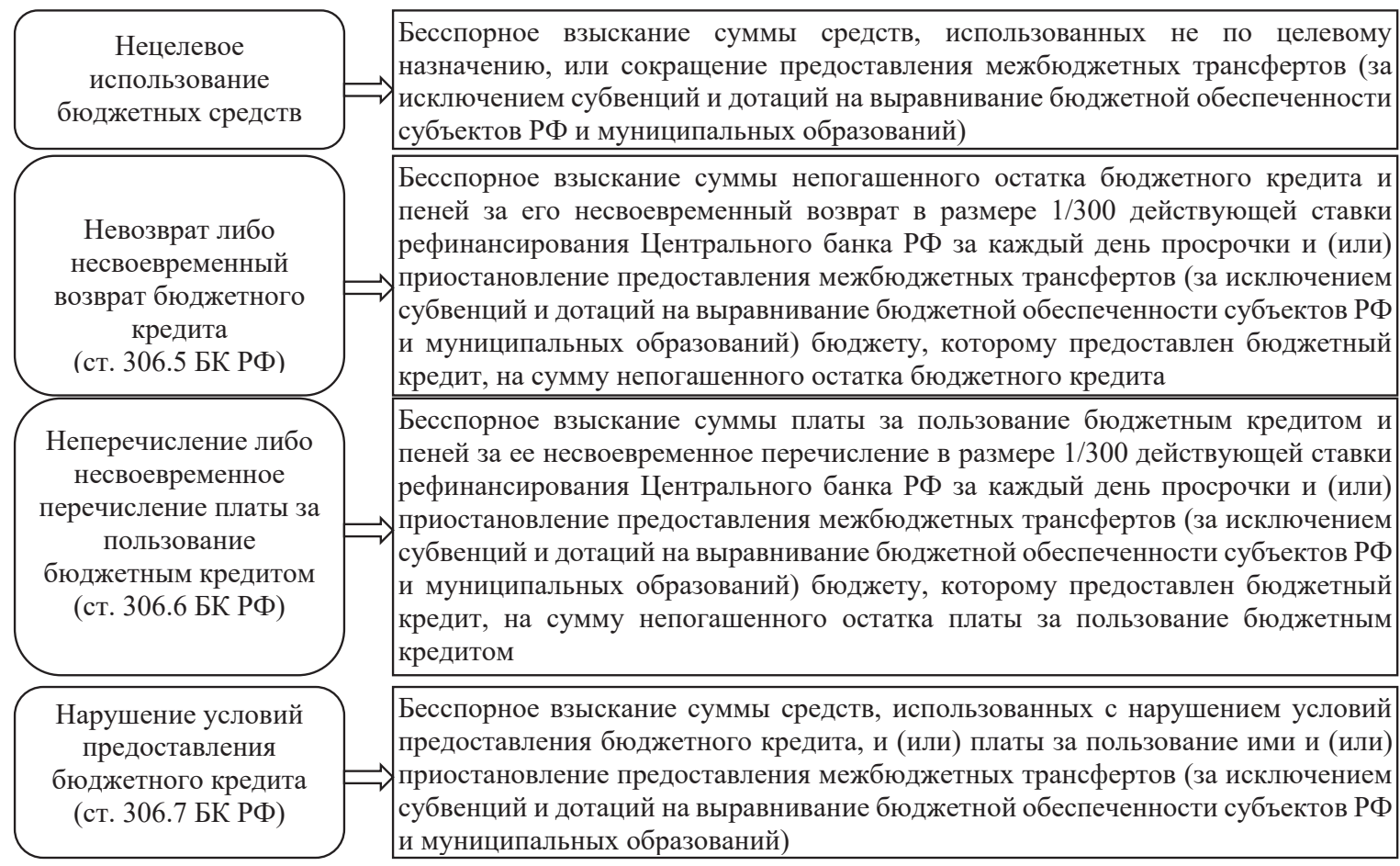

Рисунок 1. Виды бюджетных нарушений и бюджетные меры принуждения Источник: составлено по материалам [1]. 
Перечень статей, предусматривающих административную ответственность за правонарушения в бюджетной сфере.

15.15 Невозврат либо несвоевременный возврат бюджетного кредита

15.15.1- Неперечисление либо несвоевременное перечисление платы за пользование бюджетным кредитом

15.15.2 - Нарушение условий предоставления бюджетного кредита

15.15.3- Нарушение порядка и (или) условий предоставления межбюджетных трансфертов

15.15.4 Нарушение условий предоставления бюджетных инвестиций

15.15.5 -Нарушение условий предоставления субсидий

15.15.5-1 - Невыполнение государственного (муниципального) задания

15.15.6 Нарушение требований к бюджетному (бухгалтерскому) учету, в т.ч. к составлению, представлению бюджетной, бухгалтерской (финансовой) отчетности 15.15.7 - (документов), используемых при составлении и рассмотрении проектов бюджетов бюджетной системы РФ, исполнении бюджетов бюджетной системы РФ

15.15.8- Нарушение запрета на предоставление бюджетных кредитов и (или) субсидий

15.15.9- Несоответствие бюджетной росписи сводной бюджетной росписи

15.15.1 - Нарушение порядка принятия бюджетных обязательств

15.15 .1 Нарушение сроков распределения, отзыва либо доведения бюджетных ассигнований и (или) лимитов бюджетных обязательств

15.15.1 - Нарушение запрета на размещение бюджетных средств

15.15 .1 Нарушение сроков обслуживания и погашения государственного (муниципального) долга

15.15.1 - Нарушение срока направления информации о результатах рассмотрения дела в суде

15.15.1 - Нарушение порядка формирования государственного (муниципального) задания

5.15.1 Нарушение исполнения платежных документов и представления органа Федерального казначейства

Рисунок 2. Административная ответственность за правонарушения в бюджетной сфере РФ Источник: составлено по материалам [2]. 
За нарушение бюджетных правоотношений, регулируемых БК РФ, предусмотрено применение бюджетных мер принуждения, мер административной и уголовной ответственности.

Глава 15 Кодекса РФ об административных правонарушениях (далее - КоАП РФ) содержит статьи, предусматривающие меры административной ответственности в части нарушения бюджетного законодательства, представленные на рисунке 2.

КоАП РФ устанавливает меры ответственности за нецелевое использование средств (ст. 15.4 КоАП РФ), а Уголовный Кодекс РФ (далее - УК РФ) - за их нецелевое расходование (ст. 285.1 УК РФ). Отличие данных понятий представлено на рисунке 3 [3].

Меры уголовной ответственности за совершенные уголовно-правовые деяния в части расходования средств на федеральные проек- ты по ст. 285.1 УК РФ могут сочетаться с наказаниями, предусмотренными иными статьями УК, в частности ст. 159 «Мошенничество», ст. 160 «Присвоение или растрата», ст. 165 «Причинение имущественного ущерба путем обмана или злоупотребления доверием», ст. 174 «Легализация (отмывание) денежных средств или иного имущества, приобретенных другими лицами преступным путем», ст. 286 «Превышение должностных полномочий», ст. 293 «Халатность».

В 2019 г. наблюдалось увеличение преступлений по ст. 285 УК РФ, включающей нецелевое расходование средств, на 1,8\% или 41 преступление (рисунок 4). Наибольшее количество злоупотреблений должностными полномочиями в 2019 г. было выявлено в Башкортостане (166 преступлений из 2297 в целом по РФ), Краснодарском крае (106), г. Москва (86) [23].

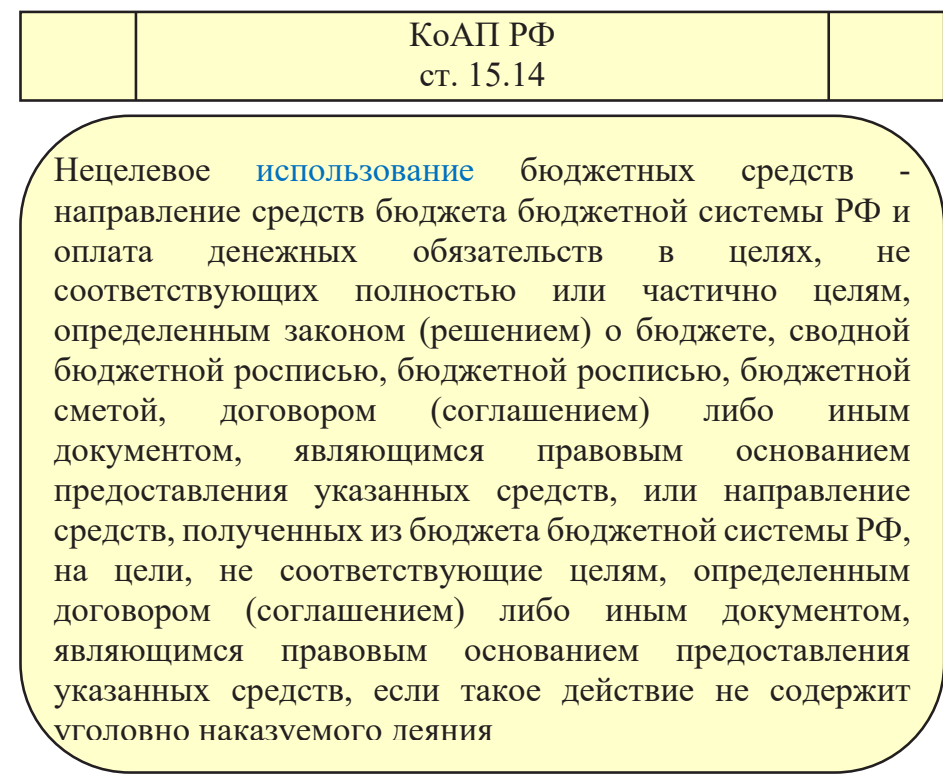

Рисунок 3. Понятия нецелевого использования и расходования бюджетных средств РФ Источник: составлено по материалам КоАП РФ и УК РФ. 


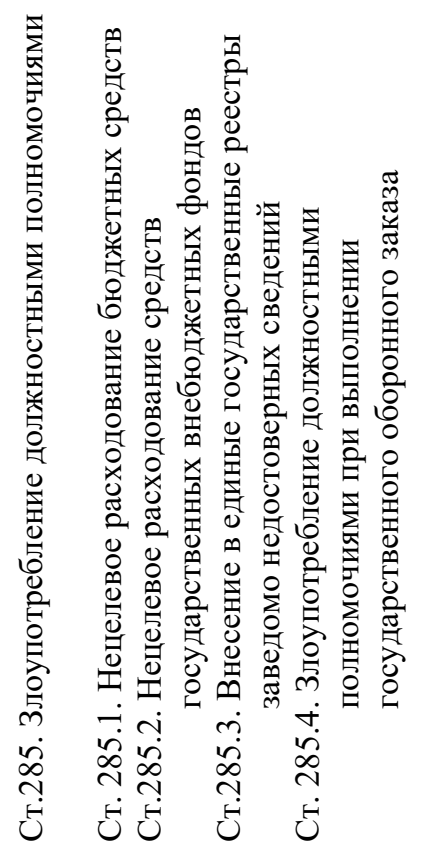

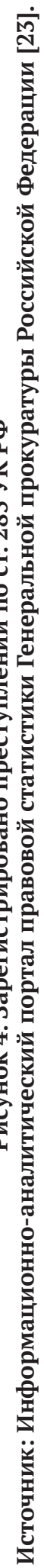

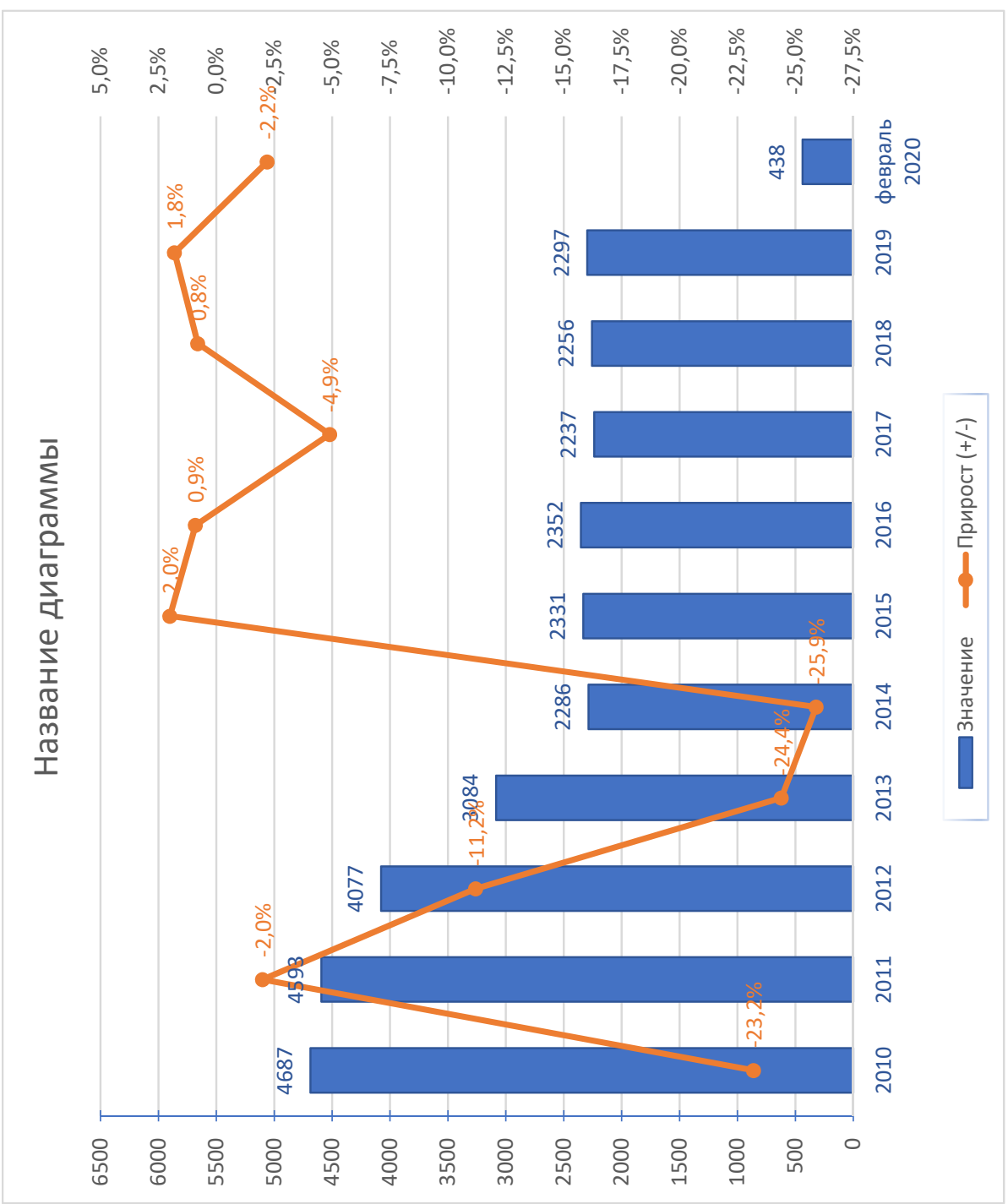




\section{Библиографический список}

1. «Бюджетный кодекс Российской Федерации» от 31.07.1998 № 145-Ф3 (ред. от 01.10.2020)// СПС КонсультантПлюс.

2. «Кодекс Российской Федерации об административных правонарушениях» от 30.12.2001 № 195-Ф3 (ред. от 31.07.2020) (с изм. и доп., вступ. в силу с 11.08.2020) // СПС КонсультантПлюс.

3. «Уголовный кодекс Российской Федерации» от 13.06.1996 № 63-Ф3 (ред. от 31.07.2020) // СПС КонсультантПлюс.

4. Федеральный закон от 05.04.2013 г. № 44-Ф3 «О контрактной системе в сфере закупок товаров, работ, услуг для обеспечения государственных и муниципальных нужд» (в ред. от 27.12.2019 г.) // СПС КонсультантПлюс.

5. Не ростом, так умом. Как национальные проекты повлияют на динамику российской экономики// Российская газета: [сайт]. - 2019. - 14 мая. - Текст: электронный. - URL: https://rg.ru/2019/05/14/kak-nacionalnyeproekty-povliiaiut-na-dinamiku-rossijskoj-ekonomiki.html.

6. Медведев обсудил с президентом РАН роль ученых в выполнении поручений из послания Путина // ТАСС: [сайт]. - 2018. - 23 марта. - Текст: электронный._URL: https://nauka.tass.ru/nauka/5058875.

7. Россия - страна технооптимистов // Всероссийский центр изучения общественного мнения: [сайт].2019. - 05 февраля. - Текст: электронный. - URL: https://wciom.ru/index.php?id=236\&uid=10151.

8. Chernysheva N.A., Perskaya V.V., Petrov A. M., Bakulina A. A. GREEN ENERGY FOR BELT AND ROAD INITIATIVE: ECONOMIC ASPECTS TODAY AND IN THE FUTURE / International Journal of Energy Economics and Policy. 2019. T. 9. № 5. C. 178-185.

9. Kevorkova Z.A., Petrov A. M., Savina N. V. TOWARDS LIABILITIES OF CORPORATE SYSTEMS / International Journal of Civil Engineering and Technology. 2019. T. 10. № 2. C. 1582-1593.

10. Petrov A.M., Nikiforova E.V., Kiseleva N.P., Grishkina S. N., Lihtarova O.V. CREATION OF THE REPORTING ON SUSTAINABLE DEVELOPMENT OF COMPANIES BASED ON SOCIOECONOMIC MEASUREMENT STATISTICS / International Journal of Recent Technology and Engineering. 2019. T. 8. № 2. C. 4005-4012.

11. Sotnikova L.V., PolenovaS.N., Mislavskaya N.A., PetrovA.M., BasovaM.M. SUSTAINABLE DeVElOPMENT, MACRO AND MICRO LEVEL: RUSSIAN AND FOREIGN MODEL / International Journal of Recent Technology and Engineering. 2019. T. 8. № 2. C. 4524-4532.

12. Kosolapova M.V., Muravitskaya N.K., Tolmachev M. N., Melnikova L.A., PetrovA.M. TECHNOLOGY FOR SOLVING THE PROBLEMS RELATED TO THE IMPLEMENTATION OF THE CONCEPT OF PRESERVING CAPITAL IN ACCOUNTING AND STATISTICS / International Journal of Recent Technology and Engineering. 2019. T. 8. № 3. C. 789-792.

13. Kosolapova M.V., PetrovA.M., YshanovI.G., Muravitskaya N.K., NurmuhamedovaH.S. THE ECONOMIC SIGNIFICANCE OF STATISTICAL RESEARCH ACTIVITIES OF REPRESENTATIVE OFFICES OF COMPANIES ABROAD / International Journal of Innovative Technology and Exploring Engineering. 2019. T. 8. № 10. C. 27132722.

14. Petrov A.M., Yurasova I. O., Putihin Y.E., Poluleh M. V., Erohina V.N. ACCOUNTANT MODELING TECHNOLOGY AND STATISTICS IN THE CONTEXT OF THE NEW EDUCATIONAL CONCEPT / International Journal of Innovative Technology and Exploring Engineering. 2019. T. 8. № 12. C. 3214-3217.

15. Petrov A.M., Kiseleva N.P., Kevorkova Z.A., Melnikova L.A., YshanovI.G. PRESENT DEVELOPMENT PRACTICES FOR TAX, FINANCIAL AND STATISTICAL REPORTING IN THE RUSSIAN FEDERATION / International Journal of Innovative Technology and Exploring Engineering. 2019. T. 8. № 12. C. 3538-3542.

16. Karpova T.P., Petrov A.M., Antonova O.V. DIRECTIONS OF ACCOUNTING DEVELOPMENT IN THE CONDITIONS OF DIGITALIZATION / Journal of Advanced Research in Dynamical and Control Systems. 2018. T. 10. № 7 Special Issue. C. $117-125$

17. Lymar M.P., Kevorkova Z.A., Petrov A. M. THE CONVERGENCE OF NATIONAL AND INTERNATIONAL ACCOUNTING STANDARDS: CHINESE EXPERIENCE / International Journal of Civil Engineering and Technology. 2018. T. 9. № 13. C. 82-94.

18. Бабаев Ю.А., Друикая М. В., Кеворкова Ж. А., Листопад Е. Е., Петров А. М. БУХГАЛТЕРСКИЙ УЧЕТ, АНАЛИЗ И АУДИТ ВНЕШНЕЭКОНОМИЧЕСКОЙ ДЕЯТЕЛЬНОСТИ / учебник для студентов обучающихся по специальности 080109 «Бухгалтерский учет, анализ и аудит» / под редакцией Ю.А. Бабаева. Москва, 2010.

19. Петров А.М., ПолоУс Е.А. ПОВЫШЕНИЕ ТРАНСПАРЕНТНОСТИ ПОКАЗАТЕЛЯ ДЕБИТОРСКОЙ ЗАДОЛЖЕННОСТИ В ОТЧЕТНОСТИ / Международный бухгалтерский учет. 2011. № 6 (156). С. 2-12. 
20. Карпова Т.П., Петров А. М., Горбаткова Г. А., Самарина Л.Б., Дашкина Г. Г., Сидорова М. И., Сабанин Р. Л., Ситникова B. А., ЛистопадЕ.Е. БУХГАЛТЕРСКИЙ УЧЕТ В СФЕРЕ УСЛУГ / учебник дЛя студентов высшего профессионального образования, обучающихся по специальности 080109 «Бухгалтерский учет, анализ и аудит» / Под редакцией М.А. Вахрушиной; Москва, 2011. Сер. Читай

21. Петров А.М., МельниковаЛ.А. ФОРМИРОВАНИЕ ОТЧЕТНОСТИ В СООТВЕТСТВИИ С ТРЕБОВАНИЯМИ МСФО КАК ОБЪЕКТИВНАЯ НЕОБХОДИМОСТЬ НА СОВРЕМЕННОМ ЭТАПЕ РАЗВИТИЯ ЭКОНОМИКИ РФ / Проблемы современной экономики. 2017. № 2 (62). С. 105-107.

22. ТЕОРИЯ БУХГАЛТЕРСКОГО УЧЕТА / учебник / Ю.А.Бабаев, А.М.Петров; под ред. Ю.А.Бабаева. Москва, Проспект, 2011. (Изд. 5-е, перераб. и доп.)

23. Зарегистрировано преступлений по ст. 285 - злоупотребление должностными полномочиями: Динамика // Информационно-аналитический портал правовой статистики Генеральной прокуратуры Российской Федерации.-Текст: электронный.-URL: http://crimestat.ru/offenses_chart. 